The Naming of the Telescope

By Edward Rosen. Pp. xvi $+110+5$ plates. (New York: Henry S thuman, 1947.) 2.50 dollars.

D. E. ROSEN Ras written a remarkably lively little bopkrthe griclusion of which is that the term 'telesco we originally devised by John Demisianj oenhalonia, and made public by Frederick Cesi at the banquet given in honour of Galileo on April 14, 1611. The circumstances may se 9 the man of science of to-day to be too minute to warrant the publication of a book; but we must welcome here what the history of science so notably lacks, namely, a painstaking and detailed inquiry into a doubtful point concerning which both contemporaries and historians are at variance. The book scarcely needs to justify itself by its subject-matter, for such is the gusto of its author that the reader is infected by that strange passion that keeps sensible men out of bed after midnight to read detective stories.

The book is accurate and scholarly as well as lively, though the reviewer confesses a shudder at the statement that Frederick Cesi, Theophilus Müller and Henry Corvinus "hiked from the castle of the illustrious marquis at St. Polo to lofty Mit. Gennaro". Let us have a translation either into English or American, not a macaronic of the two, as inappropriate as the vision which it conjures up of Cesi in short pants.

The last section of the book glances at a few of the terms other than telescopium used for this instrument; such a study might, indeed, have been carried further, and would have revealed some interesting usages. Thus, Henry More speaks of a "Galileo's tube", and Henry Vaughan gives two other synonyms in a well-known verse, which affords one of the few examples of successful scientific simile :

Either disperse these mists, which blot and fill

My perspective still as they pass;

Or else remove me hence unto that hill, Where I shall need no glass.

$$
\text { Spe }
$$

\section{F. SHERWOOD TAYLOR}

\section{Reagents for Qualitative Inorganic Analysis}

Editors: P. E. Wenger and R. Duckert; JointAuthors: C. J. Van Nieuwenburg and J. Gillis. (Second Report of the International Committee on New Analytical. Reactions and Reagents of the International Loj Sh of Chemistry.) Pp. xxii +379 . (New Yorb Amsterdam: Elsevier Publishing Co., Inc.; 10 ondon: Cleaver-Hume Press, Ltd.,
1948.) $39 s$. $6 d$.

D EAGENTS for the identification of inorganic radxals have been proposed in profusion; on the Qher hand, published descriptions often lack information on their limitations. The International Committee on New Analytical Reactions and Reagents of the International Union of Chemistry, in its report of 1938 , made a selection of reagents for study to which have been added any offering promise that appeared afterwards. Despite the difficulties of the times, the Committee was ready in 1943 to consider publication, but it was not until 1945 that the "Deuxième Rapport"' appeared ; some additions, in particular a selection of photomicrographs, have been made for the present English text.

Only reagents commonly available or readily prepared have been considered; in the latter case, brief preparative details are given. Where there are very many possibilities for any one ion, about half a dozen have been chosen. The general arrangement is simple: first, a statement of the mechanism of reaction (if known or presumed), then details of the test (which may be under the microscope, on spotplate, on paper or in test-tube, micro- or macro-), and, finally, limitations of sensitivity and selectivity. These last are the most important features of the work, for it is essential to know if and how the presence of other substances affect the delicacy of a test. Group separations are described separately.

Here, then, we have an unbiased and critical selection and survey of a large number of qualitative reactions; the value of this work needs no stressing. The style of production is generous by our standards; an extensive bibliography is included. Very occasion. ally, phraseology is rather quaint, but not so as to obscure the meaning.

New Song in a Strange Land

By Esther Warner. Pp. xi+302. (London: Victor Gollanez, Ltd., 1949.) 16s. net.

7 HE strange Ad which inspired this new song 1 is Liberja 9 out anyone who reads this book to find out somything about that country is unlikely to be much wiser by the time he has finished than when he befan. Nearly all Mrs. Warner has to say has alreadybeen said about every other part of the west coast of Africa, from Dakar to the Cameroons. It is not a Hew song, but the old, old story, told for American readers. But one can forgive Mrs. Warner a lot, for she writes in the main about simple, ordinary folk who she clearly came to love, and although her rendering of the song is so melo. dramatic as to be almost nauseous in parts, it is redeemed by this obvious sympathy-but only just. Of the true Americo-Liberians, Mrs. Warner has little to say; but one is left with the impression that if one wishes to seek for exploitation and oppression on the west coast of Africa to-day, the most likely place to find it is not in the territories of the European Colonial powers but in this free republic administered by America's god-children. One or two of Jo Dendel's woodeuts are pleasing; the rest are so trifling that it is difficult to see why they were included.

The Harold Whitaker Collection of County Atlases, Road-Books and Maps presented to the University of Leeds

A Catalogue by Dr. Harold Whitaker. Pp. 143. (Leeds : Brfofton Library, The University, 1947.) rHIS catalogue of the private collection of Dr. 1 Harold Whitaker is invaluable not only as a model of its Nnd-in which it follows the methods already addet by the author in his similar works on Yorkshire Lancashire and Cheshire-but also as illustrating the development of cartography, more particularly in England, from the sixteenth to the nineteenth centuries. It records some maps not already noticed in standard works, insludes one item not previously known, and has, in addition to the main catalogue, brief appendixes on road books, maps of Yorkshire and general atlases. There are a number of black-and-white illustrations. Dr. Whitaker has generously given the whole collection to the University of Leeds, the librarian of which contributes an introduction to this excellent work.

J. N. L. B. 